\title{
POLARIZATION CONVERSION DEVICE \\ BASED ON A WAVEGUIDE WITH PINS
}

\section{A.V. Bulashenko', S.I. Piltyay ${ }^{1}$, V.Y.Dmytrenko' ${ }^{1}$, O.V. Bulashenko ${ }^{2}$}

${ }^{1}$ Igor Sikorsky Kyiv Polytechnic Institute, Kyiv, Ukraine

${ }^{2}$ Ivan Kozhedub Shostka Professional College of Sumy State University

a.bulashenko@kpi.ua, crosspolar@ukr.net,dmitrenkovitalina6@gmail.com,

ol_bulashenko@ukr.net

Today, one of the key elements of antenna systems engaged in polarization signal processing are polarization devices. These devices are used to convert the types of polarization. The following designs of polarizers in the form of waveguide structures with posts [1-3], irises [4-8], ridged structures [9], polarizers with thin metal septum [10-13] are known. The designs of polarizing devices in the form of slots [14-16] are complex in design. Phase shifters and filters also had such constructions [17-20]. In addition, polarizers are built directly into antennas [21-23].

The 3-D model of the polarizer device is present in Fig. 1.

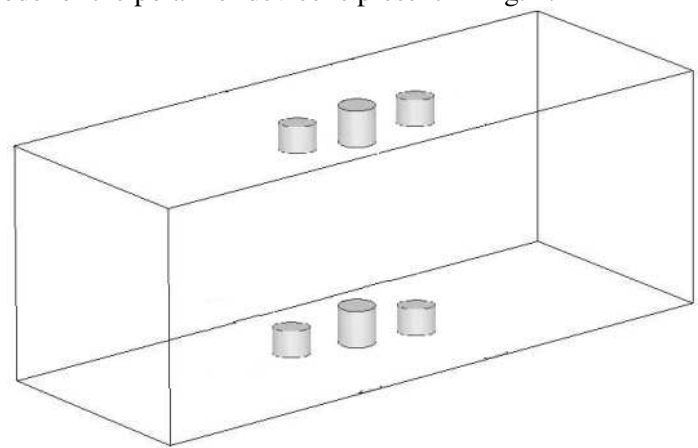

Figure. 1. 3-D model of the polarization conversion device

The design of the waveguide polarizer is shown in Fig. 2. The structure contains two posts of height $h_{1}$ and diameter $d$, one post of height $h_{2}$ and diameter $d$, the distance between the posts is $l$. Moreover, the height of the central post $h_{2}$ is greater than the height of the other posts $h_{l}$.
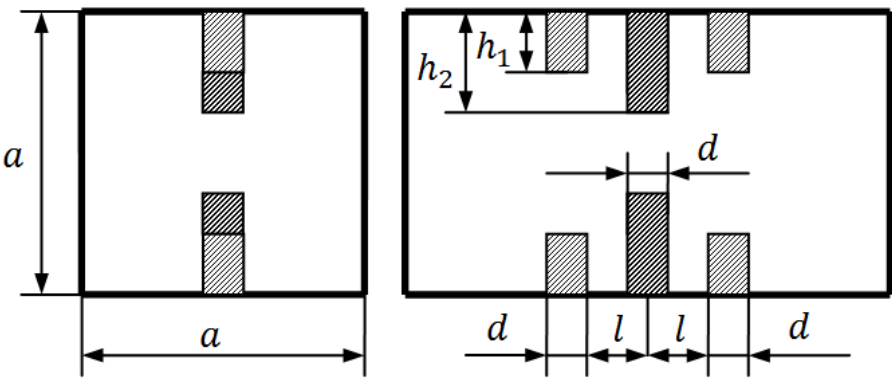

Figure. 2. Polarizer design based on a waveguide with three posts 
The presence of a cylindrical post allows you to adjust the characteristics of the device by changing the length of the post.

The characteristics of the polarizer are as follows: phase, matching and polarization [24-26]. Phase and matching are the differential phase shift and the voltage stand wave ratio (VSWR). The polarizing characteristics of a polarizer are the axial ratio and the crosspolar discrimination (XPD).

We form general wave matrices on the basis of the theory of microwave, having broken the circuit of the polarizer into smaller circuits

$$
\begin{gathered}
{\left[S_{\Sigma}\right]=\left[\begin{array}{ll}
S_{\sum 11} & S_{\sum 12} \\
S_{\sum 21} & S_{\Sigma 22}
\end{array}\right]=\frac{1}{T_{\Sigma 11}}\left[\begin{array}{cc}
T_{\sum 21} & |T| \\
1 & -T_{\sum 12}
\end{array}\right],} \\
{\left[T_{\Sigma}\right]=\left[T_{1}\right] \cdot\left[T_{2}\right] \cdot\left[T_{3}\right] \cdot\left[T_{4}\right] \cdot\left[T_{5}\right]=\left[\begin{array}{cc}
T_{\sum 11} & T_{\sum 12} \\
T_{\sum 21} & T_{\sum 22}
\end{array}\right],} \\
{\left[T_{2}\right]=\left[T_{4}\right]=\left[\begin{array}{cc}
e^{j \theta} & 0 \\
0 & e^{-j \theta}
\end{array}\right],} \\
{\left[T_{1}\right]=\left[T_{5}\right]=\frac{1}{2}\left[\begin{array}{cc}
2+Y_{p 1} & -Y_{p 1} \\
-Y_{p 1} & 2-Y_{p 1}
\end{array}\right],} \\
{\left[T_{3}\right]=\frac{1}{2}\left[\begin{array}{cc}
2+Y_{p 2} & -Y_{p 2} \\
-Y_{p 2} & 2-Y_{p 2}
\end{array}\right],}
\end{gathered}
$$

where $Y_{p}$ is the conductivity of the post, $\theta$ is electric line length.

Differential phase shift is determined by the expression

$$
\Delta \varphi=\varphi_{\Sigma 21 . L}-\beta l \text {. }
$$

VSWR is determined by the formula

$$
V S W R=\left[1+\left|S_{11}\right|\right] /\left[1-\left|S_{11}\right|\right] .
$$

The axial ratio is determined

$$
r=10 \lg \left(\frac{A^{2}+B^{2}+\sqrt{A^{4}+B^{4}+2 A^{2} B^{2} \cos (\Delta \varphi)}}{A^{2}+B^{2}-\sqrt{A^{4}+B^{4}+2 A^{2} B^{2} \cos (\Delta \varphi)}}\right),
$$

where $A=1, B=\left|S_{21}\right|$.

$\mathrm{XPD}$ is calculated by the formula

$$
X P D=20 \lg \left[\left(10^{0.05 r}+1\right) /\left(10^{0.05 r}-1\right)\right] .
$$

Fig. 3 shows the matching characteristics of the mathematical model, and Fig. 4 shows the polarization characteristics of this model. 


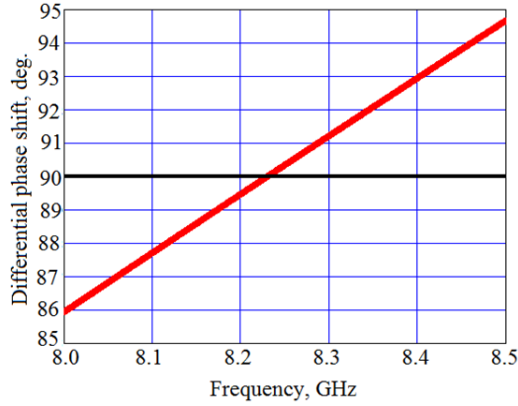

a)

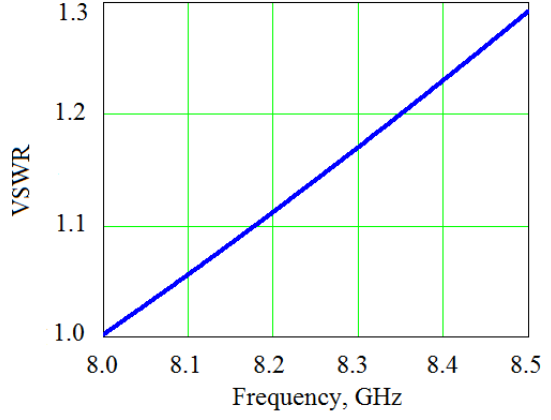

B)

Figure 3. Matching characteristics of the mathematical model

Fig. 3a demonstrates that the maximum deviation of the differential phase shift from $90^{\circ}$ is $4.5^{\circ}$. Fig. $3 \mathrm{~b}$ shows that the maximum value of VSWR is 1.28 .

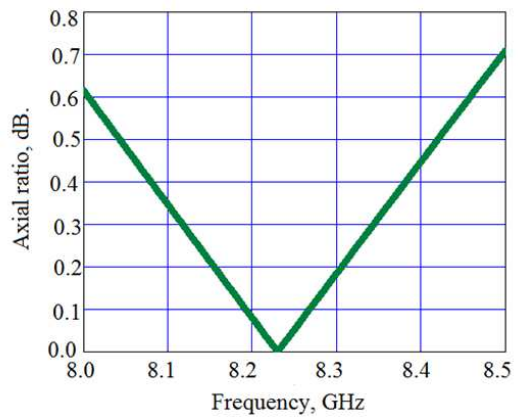

a)

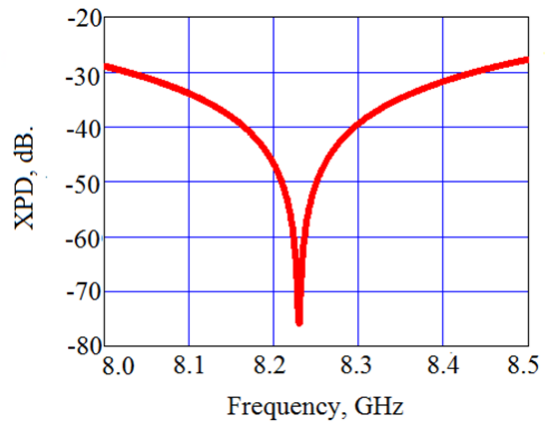

B)

Figure 4. Polarization characteristics of the mathematical model

Fig. 4 a contains the dependence of the axial ratio on the frequency, and Fig. $4 \mathrm{~b}$ contains the dependence of the XPD on the frequency. From fig. 4 we see that at a frequency of $8.5 \mathrm{GHz}$ the axial ratio acquires its maximum value of $0.71 \mathrm{~dB}$. Also at this frequency, the XPD acquires a maximum value of $29 \mathrm{~dB}$.

Fig. 5 shows the matching characteristics of the polarizer. Fig. 5 a contains the dependence of the differential phase shift on the frequency, and Fig. 5 b contains the dependence of VSWR on the frequency in the operating frequency range from $8.0 \mathrm{GHz}$ to $8.5 \mathrm{GHz}$ of the studied prototype. 


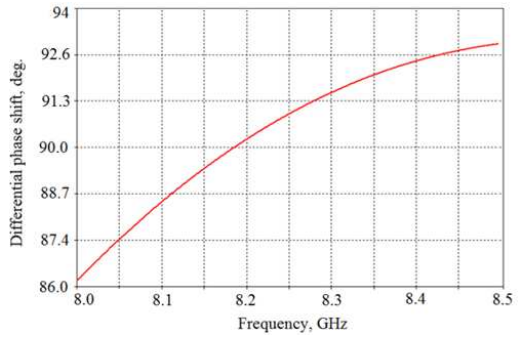

a)

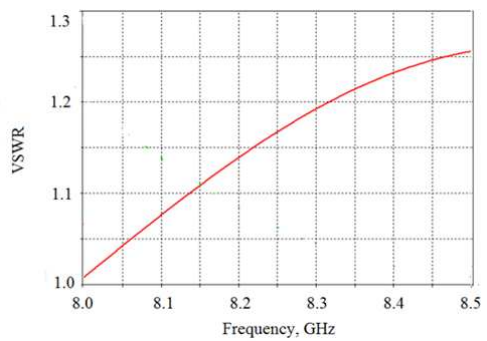

B)

Figure 5. Matching characteristics of the prototype

Fig. 5a demonstrates that the maximum deviation of the differential phase shift from $90^{\circ}$ is $4.2^{\circ}$. Fig. $5 \mathrm{~b}$ shows that the maximum value of VSWR is 1.26 .

Fig. 6 shows the polarization characteristics of the device in the operating frequency range from $8.0 \mathrm{GHz}$ to $8.5 \mathrm{GHz}$. Fig. 6 a contains the dependence of the axial ratio on the frequency, and Fig. $6 \mathrm{~b}$ contains the dependence of the XPD on the frequency. The figure shows that at a frequency of $8.0 \mathrm{GHz}$, the axial ratio acquires its maximum value of $0.55 \mathrm{~dB}$. Also at this frequency, the XPD acquires a maximum value of $31 \mathrm{~dB}$.

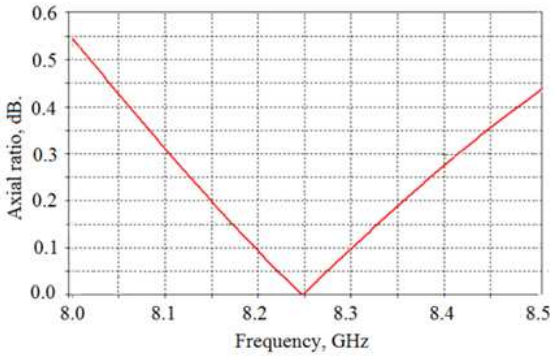

a)

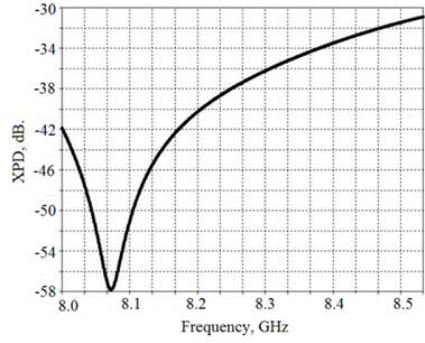

в)

Figure 5. Polarization characteristics of the prototype

Such characteristics provide the optimal design of the polarizer, which are presented in table 1.

Table 1. Optimal characteristics of the polarizer

\begin{tabular}{|c|c|c|c|c|}
\hline $\boldsymbol{a}, \mathbf{m m}$ & $\boldsymbol{l}, \mathbf{m m}$ & $\boldsymbol{h}_{\boldsymbol{l}}, \mathbf{m m}$ & $\boldsymbol{h}_{\mathbf{2}}, \mathbf{m m}$ & $\boldsymbol{d}, \mathbf{m m}$ \\
\hline 30.0 & 2.92 & 2.0 & 4.28 & 2.0 \\
\hline
\end{tabular}

As you can see, the matching and polarization characteristics of the mathematical model and prototype simulated in CST Microwave Studio coincide with the corresponding accuracy.

Thus, the developed waveguide polarizer with three posts has the following characteristics. The range of change of the differential phase shift is $90^{\circ} \pm 4.2^{\circ}$. The polarizer provides VSWR less than 1.26. Axial ratio is less than $0.55 \mathrm{~dB}$. XPD is higher than $31 \mathrm{~dB}$. 
Перелік посилань

1. Zhu Q.C. Reactance of posts in circular waveguide / Q.C. Zhu, A.G. Williamson, M.J. Neve// IEEE Transactions on Microwave Theory and Techniques. - 2007. - Vol. 55, No. 8. - pp. 1685-1688. DOI: 10.1109/TMTT.2007.901605.

2. Polishchuk A. Compact posts-based waveguide polarizer for satellite communications and radar systems / A. Polishchuk, A. Bulashenko, S. Piltyay, O. Bulashenko, I. Zabegalov. // IEEE 3rd Ukraine Conference on Electrical and Computer Engineering, Lviv, Ukraine, August 2021, pp. 78-83.

3. Piltyay S. Information resources economy in satellite systems based on new microwave polarizers with tunable post / S. Piltyay, A. Bulashenko, H. Kushnir, O. Bulashenko // Path of science. - 2020. - Vol. 6, no. 11. - pp. 5001-5009. DOI: 10.22178/pos.64-6.

4. Piltyay S.I. Waveguide iris polarizers for Ku-band satellite antenna feeds / S.I. Piltyay, A.V. Bulashenko, I.V. Demchenko // Journal of Nano- and Electronic Physics. -2020.- Vol. 12, no. 5. - pp. 05024-1-5. DOI: http://doi.org/10.21272/jnep.12(5).05024.

5. Piltyay S.I. Compact polarizers for satellite information systems / S.I. Piltyay, A.V. Bulashenko, I.V. Demchenko // IEEE International Conference on Problems of Infocommunications. Science and Technology (PIC S\&T), Kharkiv, Ukraine. - 2020. pp. 557-562. DOI: 10.1109/PICST51311.2020.9467889.

6. Piltyay S. Comparative analysis of compact satellite polarizers based on a guide with diaphragms / S. Piltyay, A. Bulashenko, I. Fesyuk, O. Bulashenko // Advanced Electromagnetics. - 2021. - Vol. 10, no. 2. - p. 44-55. DOI: 10.7716/aem.v10i2.1713.

7. Piltyay S. Development and optimization of microwave guide polarizers using equivalent network method / S. Piltyay, A. Bulashenko, V. Shuliak // Journal of Electromagnetic Waves and Applications. - 2021. - Vol. 35, 2021. DOI: 10.1080/09205071.2021.1980913.

8. Dubrovka F.F. Analytical and numerical method of constructive synthesis of optimal polarizers based on three irises in square waveguide / F.F. Dubrovka, A.V. Bulashenko, A.M. Kuprii, S.I. Piltyay // Radioelectronics and Communications Systems. - 2021. - Vol. 64, no 4. - pp. 204-215. DOI: 10.3103/S073527272104004X.

9. Tribak A. Ultra broadband low axial ratio corrugated quad-ridger polarizer / A.Tribak, A. Mediavilla, et al. // European Microwave Conferences, Rome, Italy. October 2009. - pp. 284-287. DOI: http://doi.org/10.23919/EUMC.2009.5295927.

10. Dubrovka F.F. Optimum septum polarizer design for various fractional bandwidths / F.F. Dubrovka, S.I. Piltyay, et al. // Radioelectronics and Communications Systems - 2020. - Vol. 63, no. 1. - pp. 15-23. http://doi.org/10.3103/I07352720010021.

11. Dubrovka F. Compact X-band stepped-thickness septum polarizer / F. Dubrovka, S. Piltyay, O. Sushko, et al. // IEEE Ukrainian Microwave Week, Kharkiv, Ukraine, September 2020, pp. 135-138. DOI: 10.1109/UkrMW49653.2020.9252583.

12. Dubrovka F. Circularly polarised X-band H11- and H21-modes antenna feed for monopulse autotracking ground station / F. Dubrovka et al. // IEEE Ukrainian Microwave Week, Kharkiv, Ukraine, September 2020, pp. 196-202. DOI: 10.1109/UkrMW49653.2020.9252600.

13. Deutschmann B. Broadband septum polarizer with triangular common port / B. Deutschmann, A.F. Jacob // IEEE Transactions on Microwave Theory and Techniques. - 2020. - Vol. 68, No. 2. - pp. 693-700. DOI: 10.1109/TMTT.2019.2951138.

14. Kirilenko, A.A. Application of the generalized scattering matrix technique for the dispersion analysis of 3D slow-wave structures / A.A. Kirilenko, S.L. Senkevich, 
S.O. Steshenko // Telecommunications and Radio Engineering. - 2015. - Vol. 74, no. 17. - pp. 1497-1511, 2015. DOI: 10.1615/TelecomRadEng.v74.i17.10.

15. Kulik D.Yu. Compact-size polarization rotators on the basis of irises with rectangular slots / D.Yu. Kulik,, A.O. Perov, N.G. Kolmakova // Telecommun. and Radio Engineering. - 2016. - Vol. 75, no. 10. - pp. 857-865, 2016. DOI: 10.1615/TelecomRadEng.v75.i10.10.

16. Kirilenko A.A. A tunable compact polarizer in a circular waveguide / A.A. Kirilenko, S.O. Steshenko, et al. // IEEE Transactions on Microwave Theory and Techniques. - 2019. - Vol. 67, No. 2. - pp. 592-596. DOI: $10.1109 /$ TMTT.2018.2881089.

17. Qiu L.-L. Dual-band filtering differential phase shifter using cascaded wideband phase shifter and bandstop network with two same phase shifts / L.-L. Qiu and L. Zhu // IEEE Microwave and Wireless Components Letters. - 2021. - Vol. 31, no. 3. - pp. 261-264. DOI: 10.1109/LMWC.2020.3046247.

18. Omelianenko M.Y. Waveguide planar E-plane filter with ultra-wide stopband / M.Y. Omelianenko et al.// Radioelectron. Commun. Syst. - 2020. - Vol. 63, no. 12. pp. 650-655, 2020. DOI: 10.3103/S0735272720120031.

19. Omelianenko M.Y. Stopband characteristics improvement of waveguide planar E-plane Filters / M.Y. Omelianenko et al.// Radioelectron. Commun. Syst. - 2021. Vol. 64, no. 2, pp. 53-63. DOI: 10.3103/S0735272721020011.

20. Omelianenko M.Y. E-plane stepped-impedance bandpass filter with wide stopband / M.Y. Omelianenko and T.V. Romanenko // IEEE 40th Int. Conf. on Electronics and Nano technology (ELNANO), Kyiv, Ukraine, pp. 838-841, 2020. DOI: 10.1109/ELNANO50318.2020.9088888.

21. Zabegalov I.V. Waveguide slot feed section for antennas with circular polarization / I. V. Zabegalov, V.V. Shuliak, S.I. Piltiai, A.V. Bulashenko, O. V. Bulashenko // Вісник ВПI. -2021. - Vol. 3. - pp. 105-112. DOI: 10.31649/1997-92662021-156-3-105-112.

22. Zabegalov I.V. Waveguide feed network for horn antenna with circular polarization / I.V. Zabegalov, Y.E. Sharpan, I.I. Dikhtyaruk, S.I. Piltyay, A.V. Bulashenko // Bulletin of Cherkasy State Technological University. - 2021. - Vol. 1. pp. 99-113. DOI: 10.24025/2306-4412.1.2021.229924.

23. Piltyay S. I. High performance waveguide polarizer for satellite information systems / S. I. Piltyay et al. // Visnyk Cherkaskogo derzhavnogo tekhnolohichnogo universytetu. - 2020. - Vol. 4. - pp. 14-26, 2020. DOI: 10.24025/23064412.4.2020.217129.

24. Piltyay S. Analytical modeling and optimization of new Ku-band tunable square waveguide iris-post polarizer / S.I. Piltyay et al. // International Journal of Numerical Modelling: Electronic Networks, Devices and Fields. - 2021. - Vol. 34, no. 5. - pp. 127. DOI: $10.1002 / \mathrm{JNM} .2890$.

25. Bulashenko A.V. Simulation of compact polarizers for satellite telecommunication systems with the account of thickness of irises / A.V. Bulashenko, S.I. Piltyay, I.V. Demchenko // KPI Science news. - 2021. - Vol. 1. - pp. 7-15. DOI: 10.20535/kpisn.2021.1.231202.

26. Bulashenko A.V. Waveguide polarizer with three irises for antennas of satellite television systems / A.V. Bulashenko, S.I. Piltyay, H.S. Kushnir, O.V. Bulashenko // Science-Based Technologies. - 2021. - Vol. 49, no. 1. - pp. 39-48. DOI: 10.18372/2310-5461.49.15290. 